\title{
Biofuels in Spain: Market penetration analysis and competitiveness in the automotive fuel market
}

\author{
Fernando Hernández Sobrino ${ }^{\mathrm{a}, *}$, Carlos Rodríguez Monroy ${ }^{\mathrm{a}}$, José Luîs Hernández Pérez ${ }^{\mathrm{b}}$ \\ ${ }^{a}$ Department of Business Administration, School of Industrial Engineering, Universidad Politécnica de Madrid, José Gutierrez Abascal 2, 28006 Madrid, Spain \\ ${ }^{\mathrm{b}}$ High School Chemistry Teacher, Madrid, Spain
}

Keywords:

Ethanol

Biodiesel

Biofuel

Automotive industry

Automotion fuel market

\begin{abstract}
A B S T R A C T
For several years the European Union (E.U.) has been promoting the use of biofuels due to their potential benefits such as the reduction of dependence on foreign energy imports (the raw materials can be produced within the E.U.), the more stable fossil fuel prices (they can replace fossil fuels on the market), the greenhouse gas (GHG) reduction (biofuels' raw materials fix $\mathrm{CO}_{2}$ from the atmosphere) and the fact that they can represent an additional source of income for the primary sector (biofuels' raw materials are vegetables that can be grown and harvested).

Despite the public aids (direct and indirect), biofuels are not competitive with fossil fuels at present, but it is possible that in the future the environment conditions change and biofuels might become competitive. It is difficult to assess whether this will happen or not, but it is possible to make an assessment of a future situation.

This article presents two analyses with one objective: to determine if biofuels might become competitive in the future. The first analysis examines the dependencies of two quotations which have a strong relationship with fuels: the crude oil quotation and the $\mathrm{CO}_{2}$ bond quotation. The analysis of these relationships may help to forecast the future competitiveness of biofuels. For instance, biofuels' future competitiveness will be higher if their raw material costs are not related to crude oil quotations or if they are related in a negative way (the higher the crude oil quotations the lower the raw material biofuels' cost). The second analysis focuses on the market penetration of biofuels in the Spanish market. There are data related to biofuels monthly consumption in Spain since 2007 and it is possible to know if biofuels are gaining market quota since then.
\end{abstract}

\section{Contents}

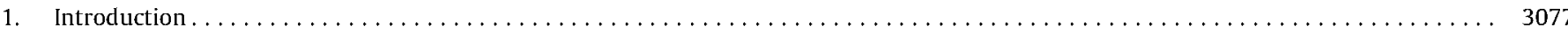

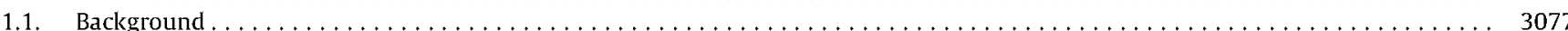

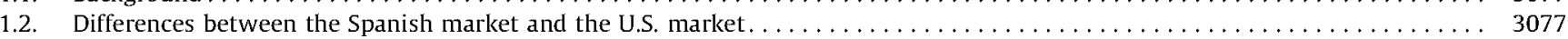

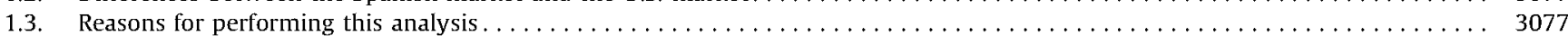

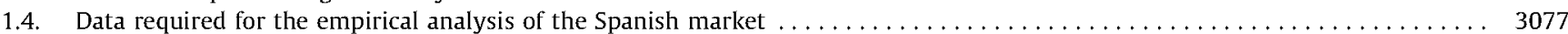

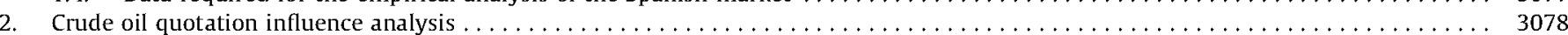

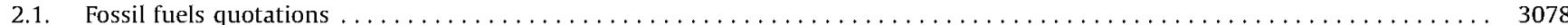

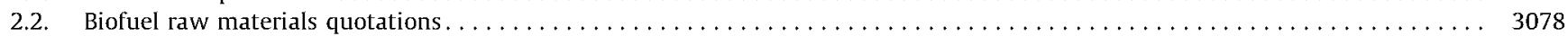

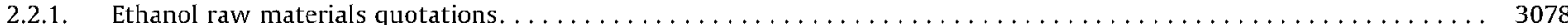

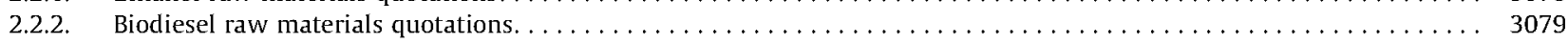

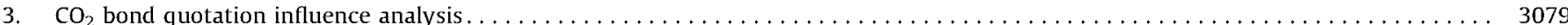

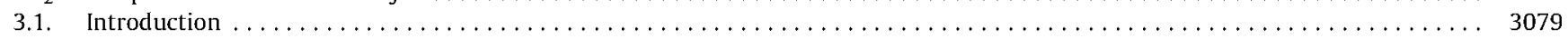

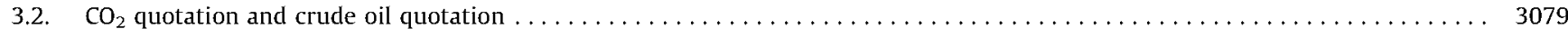

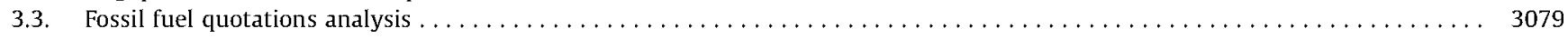

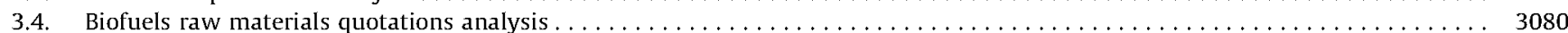

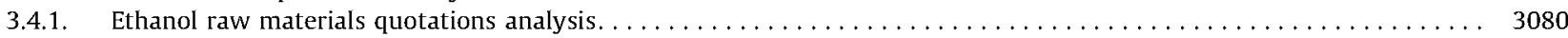

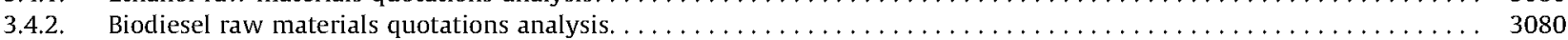

\footnotetext{
* Corresponding author. Tel.: +34915748992.

E-mail addresses: sobrinof@gmail.com (F.H. Sobrino), crmonroy@etsii.upm.es (C.R. Monroy), joseluishernandezperez@gmail.com (J.L.H. Pérez)
} 


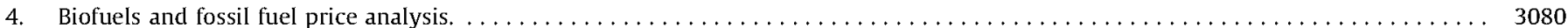

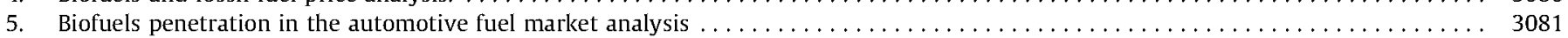

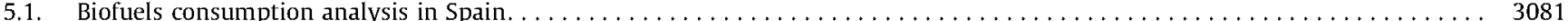

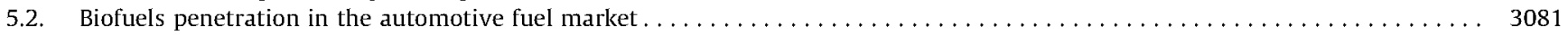

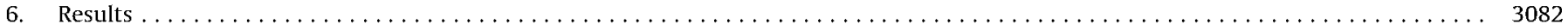

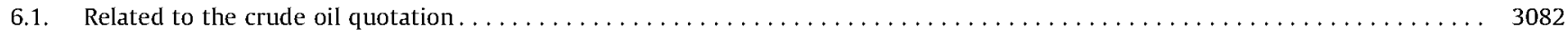

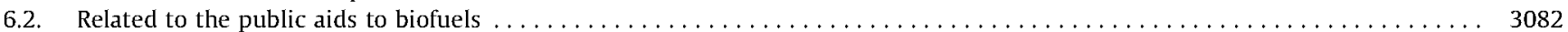

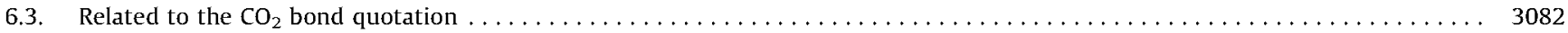

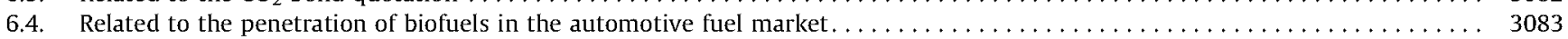

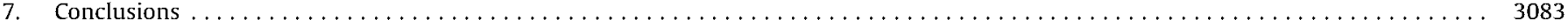

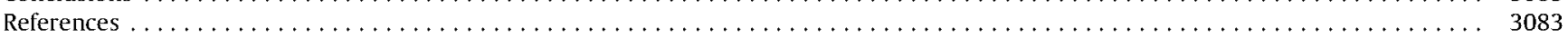

\section{Introduction}

In previous reports [1,2], the authors described the reasons which led the European Union (E.U.) to promote the use of biofuels due to their potential benefits [3]:

- Dependence reduction on foreign energy: Raw materials for biofuels can be produced internally, within the country.

- Fossil fuel price stabilization: Biofuels are products that can replace fossil fuels on the market.

- Greenhouse gases (GHG) reduction: Biofuels' raw materials fix $\mathrm{CO}_{2}$ from the atmosphere.

- Additional source of income for the primary sector: Biofuels' raw materials are vegetables.

For Spain, it was concluded that that the use of biofuels is not profitable neither from the economic nor from net GHG emissions:

- The use of ethanol and biodiesel implies depending on imports of raw materials from outside E.U. instead of depending on oil.

- Fossil fuels GHG emissions may be similar to biofuel emissions depending on the boundary conditions.

Knowing that biofuels are not profitable at the moment, the question to answer is if they will be profitable in the future. This article analyses the fossil fuels and biofuels factors in order to know if there are relationships among then. In principle, a product intended to replace an existing one will be more competitive the lower its unit price or the unit price of its raw materials price is in comparison with the existing one.

\subsection{Background}

In 2007, Ray Szulczyk [4] published an analysis related to biofuels market penetration. In that analysis, the theoretical relationships of certain factors (energy prices, technological advances, subsidies and aids for biofuel production and $\mathrm{CO}_{2}$ bond quotation) were analyzed for the U.S. market.

This report is focused on the Spanish case. Hence, the empirical relationships among different quotations are analyzed:

- Crude oil quotation (Brent) relationships to fossil fuel quotations and biofuels raw materials quotations.

- $\mathrm{CO}_{2}$ bond quotation relationships to oil quotation, fossil fuel quotations and the biofuel raw materials quotations.

Biofuels penetration in the automotive fuels market is also analyzed.

\subsection{Differences between the Spanish market and the U.S. market}

The Spanish market and the U.S. market are substantially different:
- The balances of payments on the primary market are substantially different. U.S. exports products that can be used as raw materials to obtain biofuels. However, Spain is now importing almost all the raw materials used to produce ethanol and biodiesel.

- The U.S. market volume and the Spanish market volume are essentially different. A change in U.S. oil demand might change its quotation. This is much less likely to happen in the event of a change in the Spanish demand for crude oil.

- The U.S. biofuels production aids are directed to producers. In Spain there are no direct aids to producers. Biofuels do not pay hydrocarbon special taxes.

- In the U.S. case study, the byproducts market is considered. This market is much less developed in Spain and hence, it is not considered. For instance, glycerin, a biodiesel byproduct, has no significant market.

\subsection{Reasons for performing this analysis}

As it has been already mentioned, biofuels are not competitive with fossil fuels in the automotive fuel market at the moment.

In order to know if they will be competitive in the future it is convenient to know if some biofuels parameters are correlated to fossil fuels parameters: raw materials quotations, prices, etc.

If these relationships exist, it is expected that the competitiveness of biofuels in the future will not be as good as if they did not exist. For instance, it is desirable that biofuels raw materials quotations do not depend on crude oil quotations.

\subsection{Data required for the empirical analysis of the Spanish market}

The following data are required to undertake the analysis:

- Crude oil quotation (Brent) in USD. These data were obtained from the website of the Spanish Ministry of Industry, Tourism and Trade [5]

- The $€ / \$$ rate of exchange, obtained from the Oanda website [6].

- Fossil fuels (gasoline 95 and diesel) quotations. These data were obtained from the website of the Spanish Ministry of Industry, Tourism and Trade [5].

- $\mathrm{CO}_{2}$ bond quotations in the European market. These data were obtained from the website www.ecx.eu [7].

- Biofuels raw materials weighted average quotations. The way to calculate these figures is as follows:

- Biofuels raw materials quotations (in $\$ / t$ ).

- For ethanol, a sample of raw materials shown by Canton [8] (2007-2008 campaign) has been used.

- For biodiesel, a sample of raw materials shown by Lechón et al. [9] has been used.

- A weighted average raw materials quotation has been calculated for both biofuels according to the following 
equation:

$$
\mathrm{PP}=\sum_{i=1}^{n}\left[\mathrm{PMP}_{i} \cdot \% \mathrm{MP}_{i}\right]
$$

where

- PP is the biofuel raw material monthly average quotation in $\$ / \mathrm{t}$.

- $\mathrm{PMP}_{i}$ is the biofuel raw material $i$ monthly average quotation in $\$ / \mathrm{t}$.

- \% MP $i$ is the mass percentage of biofuel raw material $i$.

\section{Crude oil quotation influence analysis}

\subsection{Fossil fuels quotations}

Below is the analysis to see if there is a relationship between the cost of fossil fuels (gasoline 95 and diesel) and oil prices. Crude oil is quoted in dollars. In order to analyze the Spanish case the following data are needed:

- Crude oil quotation (\$). The unit of reference for Spain is Brent crude.

- The monthly average $\$ / €$ exchange rate.

- The monthly average gasoline 95 and diesel quotations.

Fig. 1 shows the crude oil, gasoline 95 and diesel quotations.

The gasoline 95 quotation curve and the diesel quotation curve have similar shapes. The crude oil quotation is also very similar to the previous ones. In order to evaluate the relationships between the crude oil quotation and the gasoline 95 and diesel quotations, Fig. 2 is built.

Both variables resemble straight lines. For both fuels, the Pearson correlation coefficient is 0.97 in both cases. This means that when the crude oil quotation rises, the gasoline 95 and diesel quotations rise too.

The Kolmogorov-Smirnov (K-S) test confirms that both variables are significant with a confidence level of $99 \%(\alpha=0.01$, maximum type I error probability). This means that variables are strongly correlated and that the linear curve is quite adequate for both. In other words, the higher the crude oil quotation, the higher the fossil fuel quotations (gasoline 95 and diesel) and vice versa (compliance level is 99\%).

Due to the previous relationship, it seems logical that the higher the crude oil quotation the higher the penetration of the products that may replace gasoline 95 and diesel and vice versa, unless these products also increase their quotations when the crude oil quotation rises.

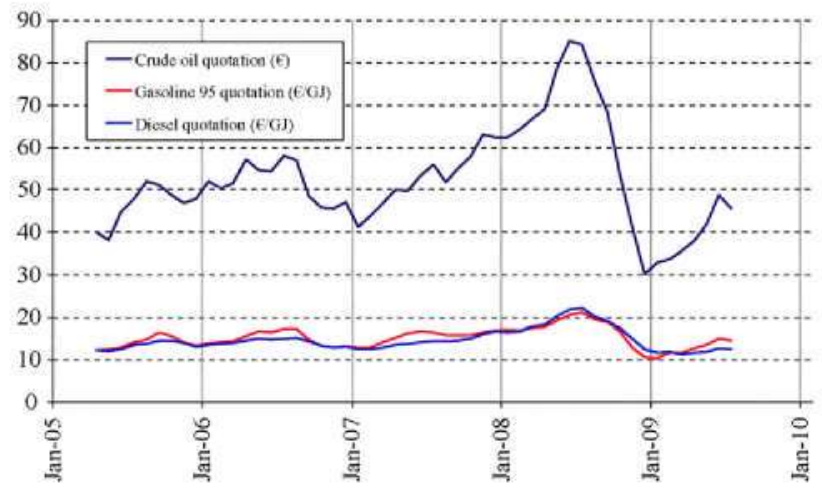

Fig. 1. Crude oil, gasoline 95 and diesel quotations - October 2003-March 2009 - 66 pairs of points. Source: Spanish Ministry of Industry, Tourism and Trade. (Figure adapted by authors.)

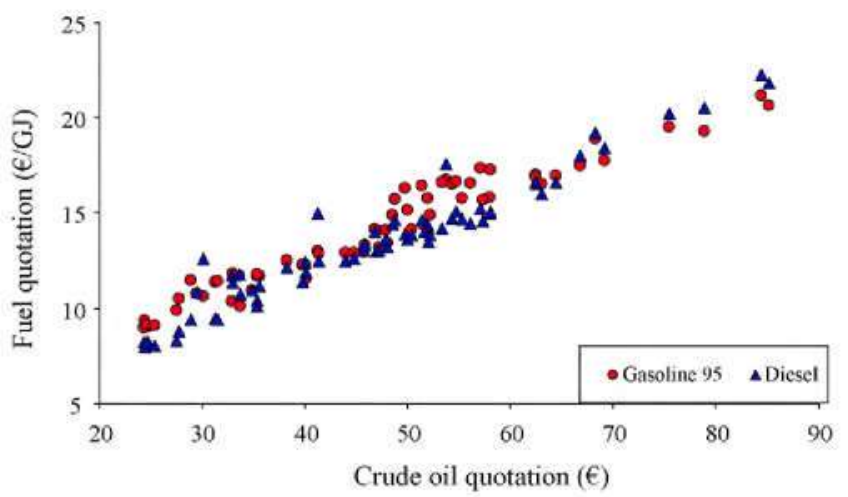

Fig. 2. Crude oil quotation vs. gasoline 95 and diesel quotations regression analysis - October 2003-March 2009 - 66 pairs of points. Source: Spanish Ministry of Industry, Tourism and Trade. (Figure adapted by authors.)

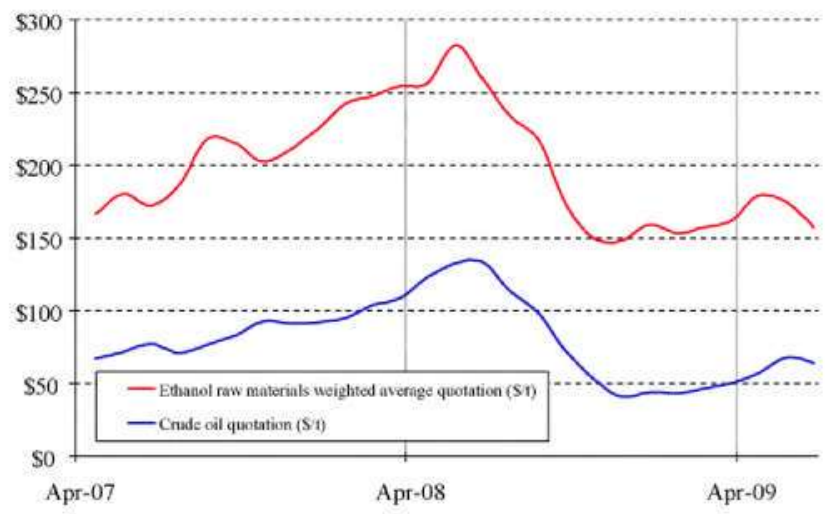

Fig. 3. Crude oil quotation (\$) vs. ethanol raw materials weighted average quotation (S/t) - May 2007-July 2009 - 27 pairs of points. Source: Spanish Ministry of Industry, Tourism and Trade, Reuters, Indexmundi.com and authors.

\subsection{Biofuel raw materials quotations}

\subsubsection{Ethanol raw materials quotations}

Fig. 3 shows the oil quotation and the ethanol raw materials weighted average quotation. Both are represented in USD because there is no point in converting then into Euros since they are quoted in USD at the origin.

Both curves have a similar shape. Fig. 4 shows crude oil quotation vs, ethanol raw materials weighted average quotation.

The Pearson correlation coefficient for linear fit is 0.95 . Hence, there is a positive correlation. The $\mathrm{K}-\mathrm{S}$ test shows that the value is significant with a confidence level of $99 \%(\alpha=0.01)$.

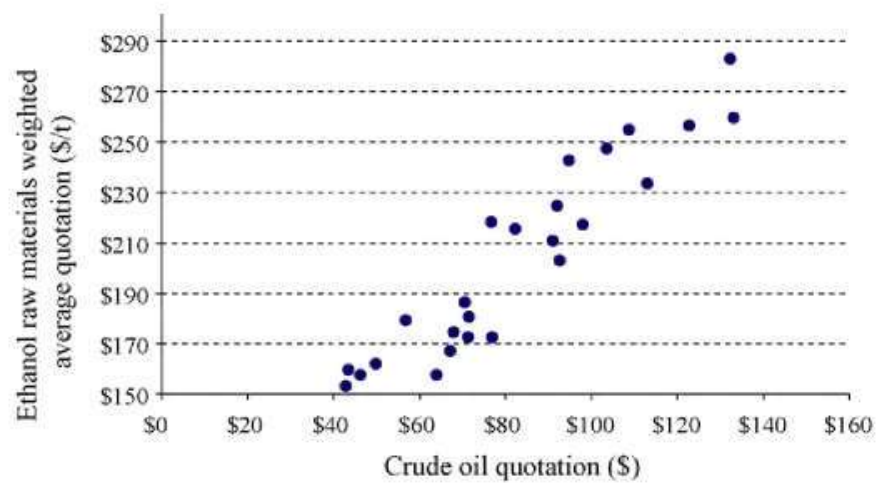

Fig. 4. Crude oil quotation vs. ethanol raw materials weighted average quotation May 2007-July 2009 - 27 pairs of points. Source: Spanish Ministry of Industry, Tourism and Trade, Reuters, Indexmundi.com and authors. 


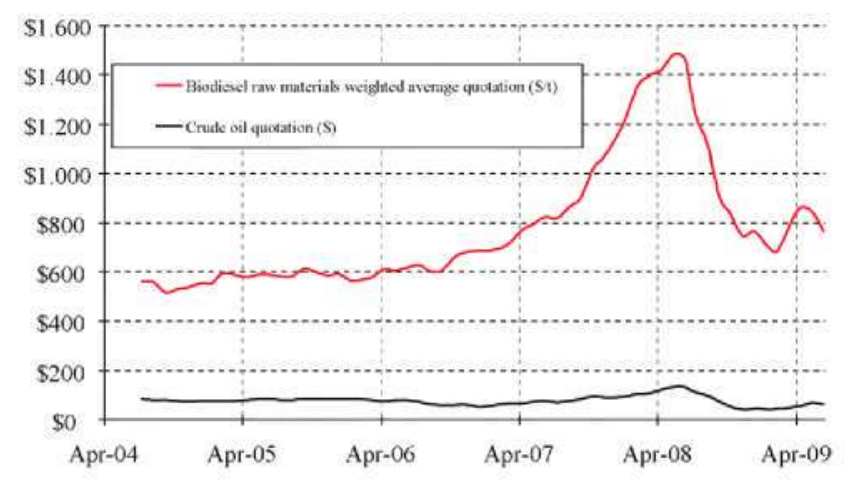

Fig. 5. Crude oil quotation (\$) vs. biodiesel raw materials weighted average quotation (\$/t). Source: Spanish Ministry of Industry, Tourism and Trade, Reuters, Indexmundi.com and authors.

\subsubsection{Biodiesel raw materials quotations}

Fig. 5 shows oil quotation and biodiesel raw materials weighted average quotation.

Both curves have a similar shape. Fig. 6 shows crude oil quotation vs. biodiesel raw materials weighted average quotation.

The figure does not show a lineal relationship between both variables but the Pearson correlation coefficient is 0.63 which indicates a positive correlation. The $\mathrm{K}-\mathrm{S}$ test shows that this value is significant with a confidence level of $99 \%(\alpha=0.01)$. In other words: the higher the crude oil quotation the higher the biofuels raw materials quotations and vice versa. Both relationships are, in principle, obstacles for biofuels to become alternatives to fossil fuels.

\section{3. $\mathrm{CO}_{2}$ bond quotation influence analysis}

\subsection{Introduction}

The $\mathrm{CO}_{2}$ bond market is an artificial market designed to reduce GHG emissions and it is one of the three mechanisms proposed in the Kyoto Protocol to accomplish its objectives [10].

The $\mathrm{CO}_{2}$ bond provides financial incentives for companies to help improve the quality of the environment by reducing $\mathrm{CO}_{2}$ emissions from its production processes.

The right to emit $\mathrm{CO}_{2}$ is considered an exchangeable commodity which is economically quantifiable by the market. Hence, companies that do not emit or minimize their emissions are rewarded and companies that emit more than allowed are penalized.

GHG emission reductions are measured in $\mathrm{CO}_{2}$ equivalent tons. These equivalent tons can be sold in the carbon market to

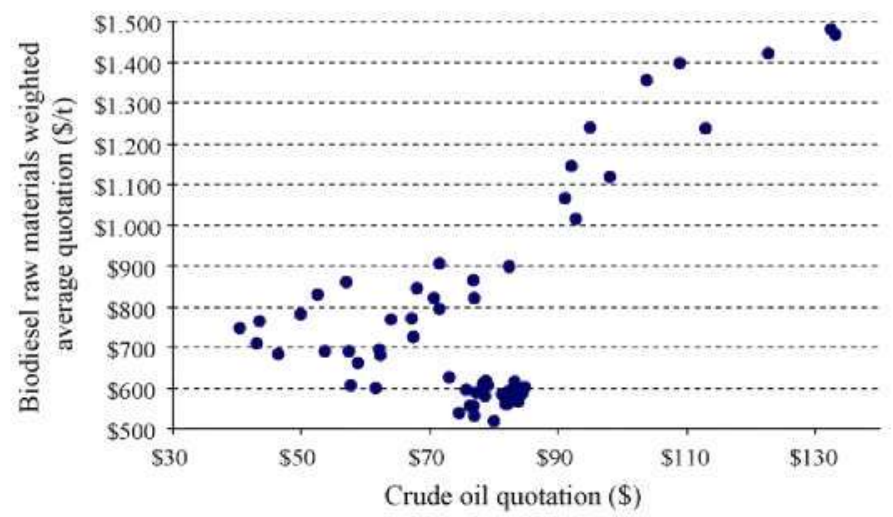

Fig. 6. Crude oil quotation (\$) vs. biodiesel raw materials weighted average quotation (( $\$ / t)$ against the weight of raw material prices used in the manufacturing of biodiesel - August 2004-July 2009 - 60 pairs of points. Source: Spanish Ministry of Industry, Tourism and Trade, Reuters, Indexmundi.com and authors.

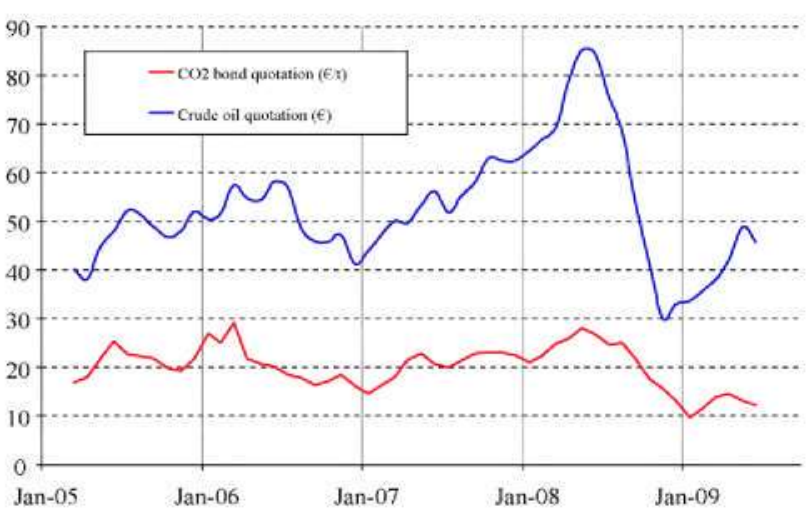

Fig. 7. Crude oil quotation ( $€$ ) and $\mathrm{CO}_{2}$ bond quotation (€/t) - April 2005-July 2009 - 52 pairs of points. Source: ecs.eu, Spanish Ministry of Industry, Tourism and Trade and authors.

industrialized countries (according to the Kyoto Protocol nomenclature). Projects that may apply for certification are renewable energy generation projects, energy efficiency improvement processes and other activities such as reforestation and cleaning of lakes and rivers.

Biofuel production may justify a GHG reduction certificate and can therefore generate $\mathrm{CO}_{2}$ bonds that can be sold in international markets. In principle, the higher the $\mathrm{CO}_{2}$ bond the higher the biofuel competitiveness in the automotive fuel market and vice versa.

\section{2. $\mathrm{CO}_{2}$ quotation and crude oil quotation}

First, the relationship between the crude oil quotation and the $\mathrm{CO}_{2}$ bond quotation is to be analyzed. Fig. 7 shows both quotations over time.

There seems to be a relationship between both quotations. Fig. 8 shows the crude oil quotation ( $€$ ) vs. the $\mathrm{CO}_{2}$ bond quotation in Europe (€).

The Pearson correlation coefficient is 0.76 , so there is a positive correlation. The $\mathrm{K}-\mathrm{S}$ test results show that this value is significant with a confidence level of $99 \%(\alpha=0.01)$. In other words, the higher the oil quotation the higher the $\mathrm{CO}_{2}$ bond quotation and vice versa.

\subsection{Fossil fuel quotations analysis}

The following analysis is performed in order to determine if the $\mathrm{CO}_{2}$ bond quotation is related to the fossil fuel quotations. Fig. 9 shows $\mathrm{CO}_{2}$, gasoline 95 and diesel quotations over time.

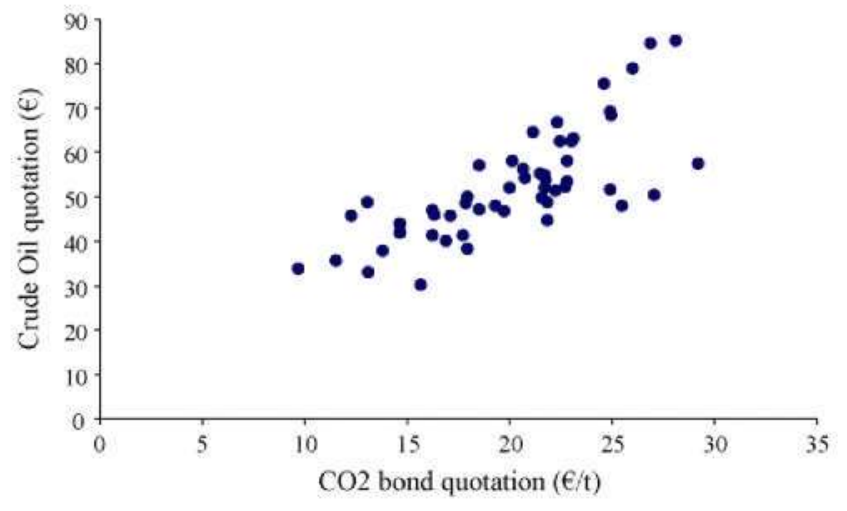

Fig. 8. Crude oil quotation ( $€$ ) vs. $\mathrm{CO}_{2}$ bond quotation ( $€ / \mathrm{t}$ ) - April 2005-July 2009 52 pairs of points. Source: ecs.eu, Spanish Ministry of Industry, Tourism and Trade and authors. 


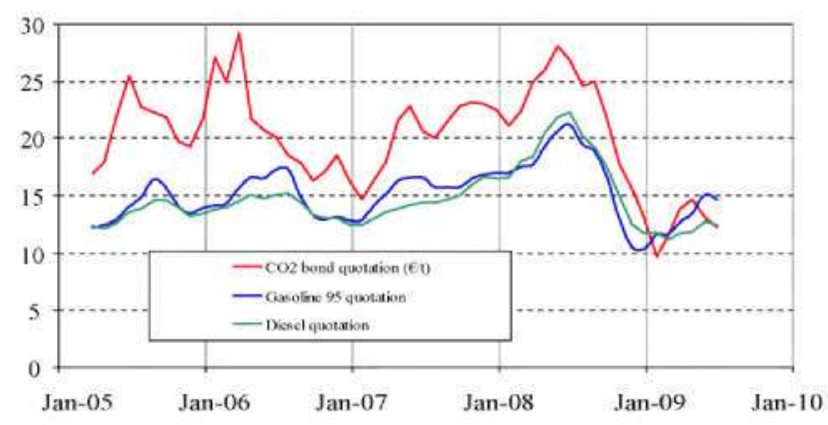

Fig. 9. $\mathrm{CO}_{2}$ bond quotation ( $€ / \mathrm{t}$ ), gasoline 95 quotation ( $€ / \mathrm{GI}$ ) and diesel quotations ( $€ / G J)$ - April 2005-July 2009 - 52 pairs of points. Source: ecs.eu, Spanish Ministry of Industry, Tourism and Trade and authors.

Figs. 10 and 11 present the $\mathrm{CO}_{2}$ bond quotations vs. the gasoline 95 and diesel quotations respectively.

These figures show that fossil fuel quotations may be related to $\mathrm{CO}_{2}$ bond quotations. The Pearson correlation coefficient is 0.71 for both cases so there are positive correlations. The $\mathrm{K}-\mathrm{S}$ test results show that these variables are significant with a confidence level of $99 \%(\alpha=0.01)$. In other words, the higher the $\mathrm{CO}_{2}$ bond quotation the higher the fossil fuel quotations and vice versa.

\subsection{Biofuels raw materials quotations analysis}

\subsubsection{Ethanol raw materials quotations analysis}

Fig. 12 shows the $\mathrm{CO}_{2}$ bond price and the ethanol raw materials weighted average quotation.

Fig. 13 shows the $\mathrm{CO}_{2}$ bond quotation vs. the ethanol raw materials weighted average quotation.

The Pearson correlation coefficient is 0.89 so there is a positive correlation. The $\mathrm{K}-\mathrm{S}$ test results that this value is significant with a confidence level of $99 \%(\alpha=0.01)$.

\subsubsection{Biodiesel raw materials quotations analysis}

Fig. 14 shows the $\mathrm{CO}_{2}$ bond quotation versus the biodiesel raw materials weighted average quotation.

Fig. 15 shows $\mathrm{CO}_{2}$ bond quotation versus biodiesel raw materials weighted average quotation.

The Pearson correlation coefficient is 0.28 so there is a positive correlation but very low. The $\mathrm{K}-\mathrm{S}$ test results that this value is significant with a confidence level of $95 \%(\alpha=0.05)$.

As a conclusion, when biofuels raw materials weighted average quotations rise, the $\mathrm{CO}_{2}$ bond quotation rises too. The confidence level is higher for ethanol raw materials than for biodiesel raw materials.

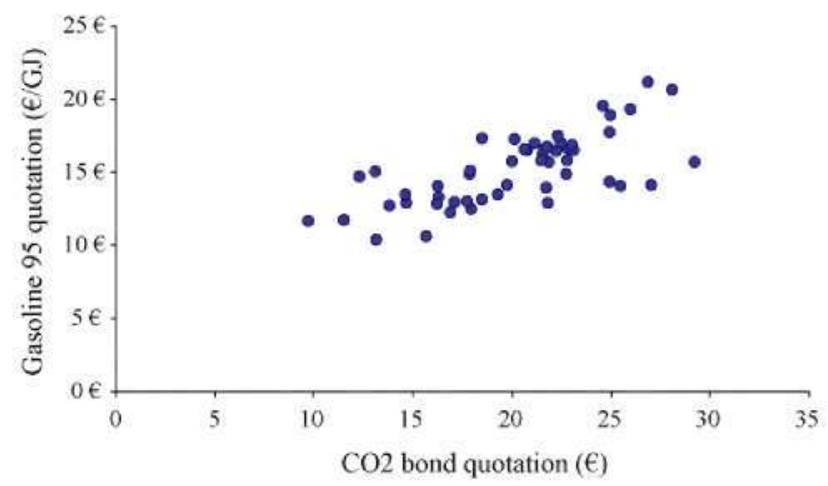

Fig. 10. Gasoline 95 quotation $(€ / \mathrm{GJ})$ vs. $\mathrm{CO}_{2}$ bond quotation $(€ / \mathrm{t})$ - April 2005-July 2009 - 52 pairs of points. Source: ecs.eu, Spanish Ministry of Industry, Tourism and Trade and authors.

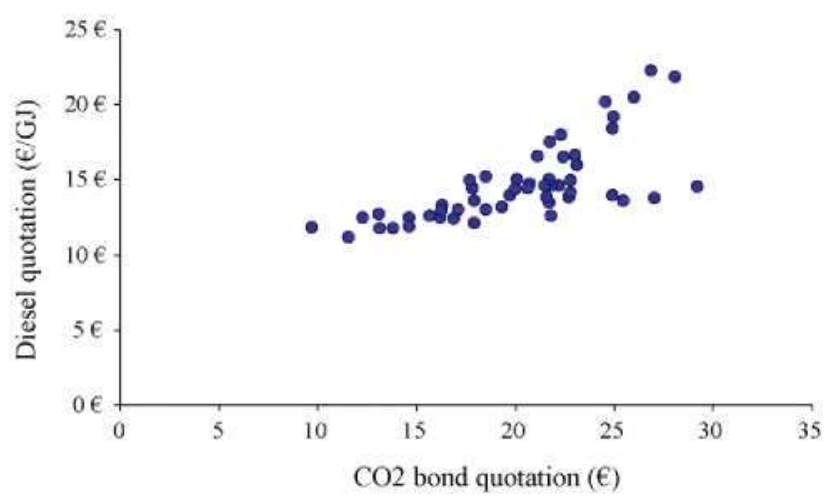

Fig. 11. Diesel quotation ( $€ / G J)$ vs. $\mathrm{CO}_{2}$ bond quotation ( $€ / \mathrm{t}$ ) - April 2005-July 2009 -52 pairs of points. Source: ecs.eu, Spanish Ministry of Industry, Tourism and Trade and authors.

\section{Biofuels and fossil fuel price analysis.}

In a previous report [2], authors analyzed the fossil fuels and biofuels price breakdowns in two dates separated by a period of 7 months: July 2008 and February 2009. Although there is no detail of E85 and biodiesel daily prices, it has been observed that prices have shifted from 0.85 to $0.869 € / 1$ for E85 and from 1.043 to $1.029 € / 1$ for biodiesel (gas station prices).

This means that ethanol cost has shifted from $0.529 € / 1$ in July 2008 to $0.600 € / 1$ in February 2009 and biodiesel has shifted from $0.750 € / 1$ in July 2008 to $0.724 € / 1$ in February 2009 .

Between those dates:

- Crude oil quotation dropped 58.11\%.

- Fossil fuels prices per volume have dropped: $23 \%$ for gasoline 95 and $25 \%$ for diesel.

- E85 and biodiesel prices remained fairly constant.

If inflation is not taken into account, it is observed that E85 is more expensive than gasoline 95 (5.28\% in July 2008 and $31.95 \%$ in February 2009). On the other hand, biodiesel is more expensive than diesel (1.50\% in July 2008 and $33.09 \%$ in February 2009).

In February 2009, production price per unit of energy of biofuels with respect to fossil fuels were considerably higher:

- From $33.76 \%$ to $88.50 \%$ for E85 versus gasoline 95 .

- From $26.19 \%$ to $76.12 \%$ for biodiesel versus diesel.

Therefore it is concluded that a sharp decrease in the crude oil quotation,

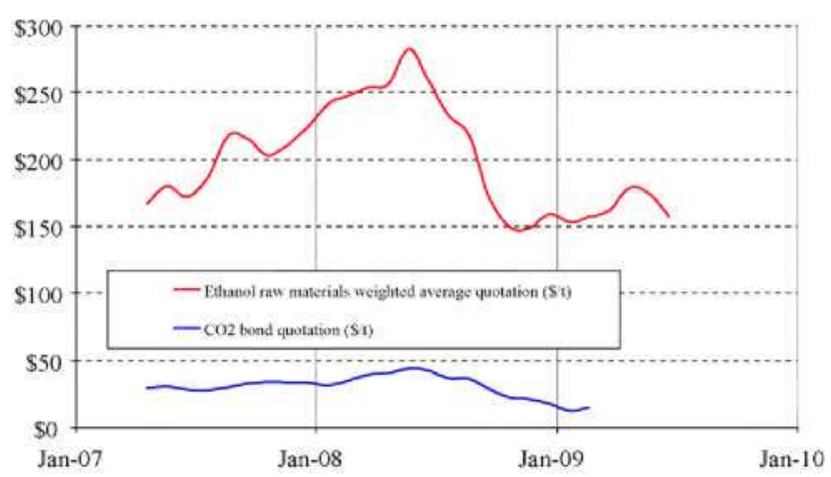

Fig. 12. $\mathrm{CO}_{2}$ bond quotation $(\mathrm{S} / \mathrm{t})$ and ethanol raw materials weighted average quotation (\$/t) - May 2007-July 2009 - 27 pairs of points. Source: ecs.eu, Spanish Ministry of Industry, Tourism and Trade and authors. 


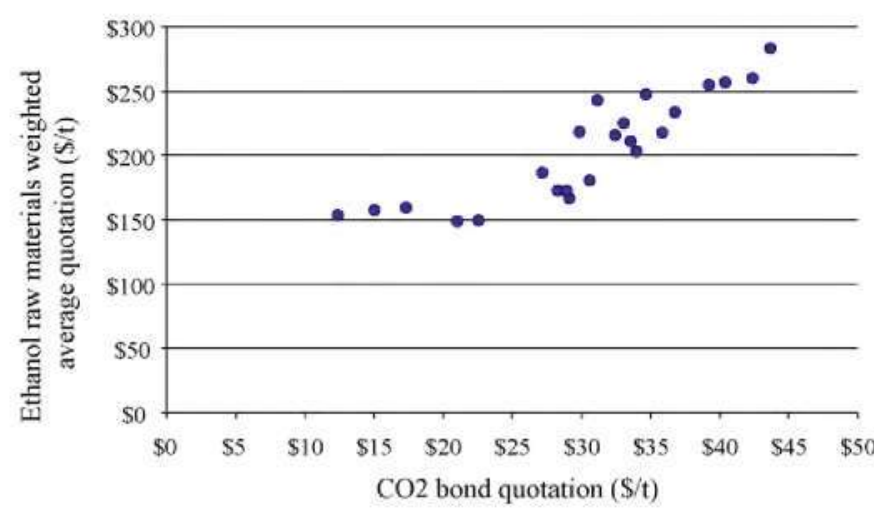

Fig. 13. $\mathrm{CO}_{2}$ bond quotation ( $\$ / \mathrm{t}$ ) vs. ethanol raw materials weighted average quotation (\$/t) - May 2007-July 2009 - 27 pairs of points. Source: ecs.eu, Spanish Ministry of Industry, Tourism and Trade and authors.

- Causes a decrease in the fossil fuel prices.

- Causes a direct reduction of fossil fuels prices per unit of energy.

- Does not cause a reduction in production costs for biofuels.

- Causes a loss of competitiveness to biofuels with respect to fossil fuels.

If the tax exception for biofuels is eliminated, the difference between biofuels and fossil fuel prices at gas stations would be much higher:

- E85 versus gasoline 95: Between $33.76 \%$ and $88.50 \%$.

- Biodiesel versus diesel: Between 26.19\% and 76.12\%.

If this tax exception is not renewed in December 2012, it is expected that a sudden reduction in biofuel consumption will occur, eliminating them from the automotive fuel market.

\section{Biofuels penetration in the automotive fuel market analysis}

An analysis to find out if biofuels are penetrating the automotive fuel market needs to be performed.

\subsection{Biofuels consumption analysis in Spain}

E85 monthly consumption is shown in Fig. 16.

Fig. 17 shows the monthly consumption of biodiesel and biodiesel blend.

These figures provide little information because the data variability is high from month to month. Hence, it is not possible to appreciate the temporality of the variables. Thus, in Figs. 18 and

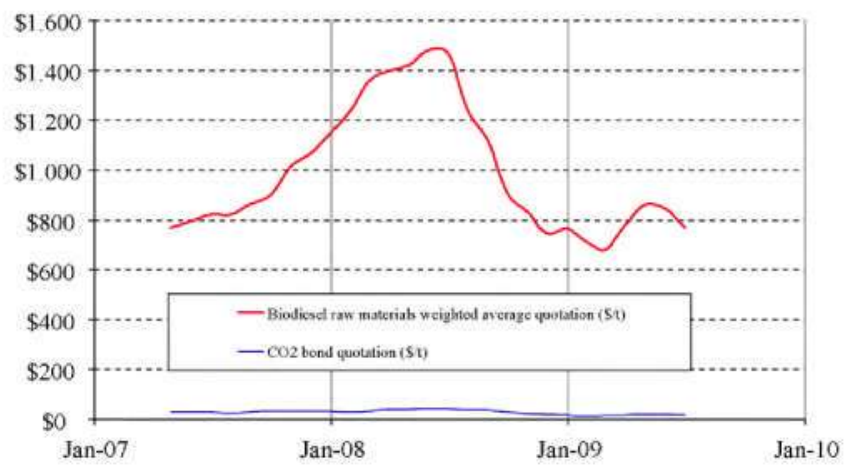

Fig. 14. $\mathrm{CO}_{2}$ bond quotation $(\$ / \mathrm{t})$ and biodiesel raw materials weighted average quotation (\$/t) - May 2007-July 2009 - 27 pairs of points. Source: ecs.eu, Spanish Ministry of Industry, Tourism and Trade and authors.

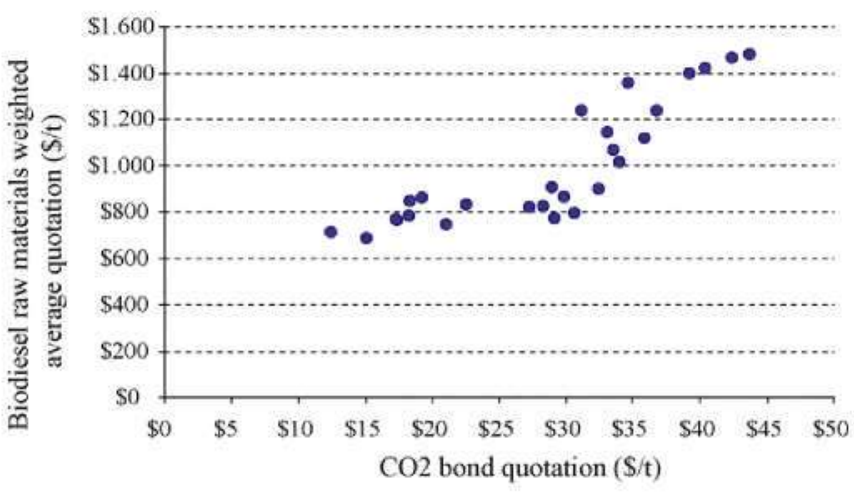

Fig. 15. $\mathrm{CO}_{2}$ bond quotation ( $\left.\$ / \mathrm{t}\right)$ and biodiesel raw materials weighted average quotation (\$/t) - May 2007-July 2009 - 27 pairs of points. Source: ecs.eu, Spanish Ministry of Industry, Tourism and Trade and authors.

19 we observe the average monthly consumption per year for E85 and biodiesel respectively.

There are only three data per biofuel. Therefore, it is not possible to elaborate a statistical study. A direct data observation is enough to check that E85 average monthly consumption has grown over the past three years and biodiesel average monthly consumption has grown between 2007 and 2008 but declined in 2009.

\subsection{Biofuels penetration in the automotive fuel market}

Fig. 20 shows ethanol and ethanol blends consumption on the total consumption of fuel for Otto cycle automotive vehicles.

Fig. 21 shows the biodiesel and biodiesel blends consumption on the total fuel consumption of diesel automotive.

For Otto cycle automobiles, ethanol blends consumption in comparison with total gasoline consumption is very small (always less than $0.015 \%$ ). For Diesel cycle automobiles, biodiesel and biodiesel blends consumption is small in comparison with diesel consumption (always less than $1.6 \%$ ).

The Pearson correlation coefficient is 0.065 for ethanol and ethanol blends and 0.237 for biodiesel and biodiesel blends. Both show a positive correlation. The K-S test results show that these variables are not significant with a confidence level of $95 \%$ $(\alpha=0.05)$. Hence it is concluded that both are poorly correlated and linear adjustments are inadequate.

In other words, it is not possible to corroborate that ethanol, biodiesel and their blends are penetrating in the automotive fuel market.

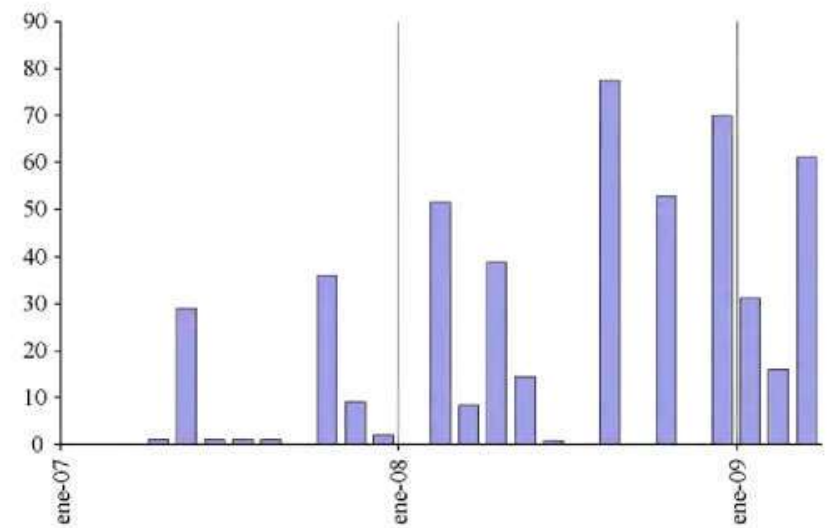

Fig. 16. E85 monthly consumption (t) - January 2007-March $2009-27$ pairs of points. Source: cores.es [11] and authors. 


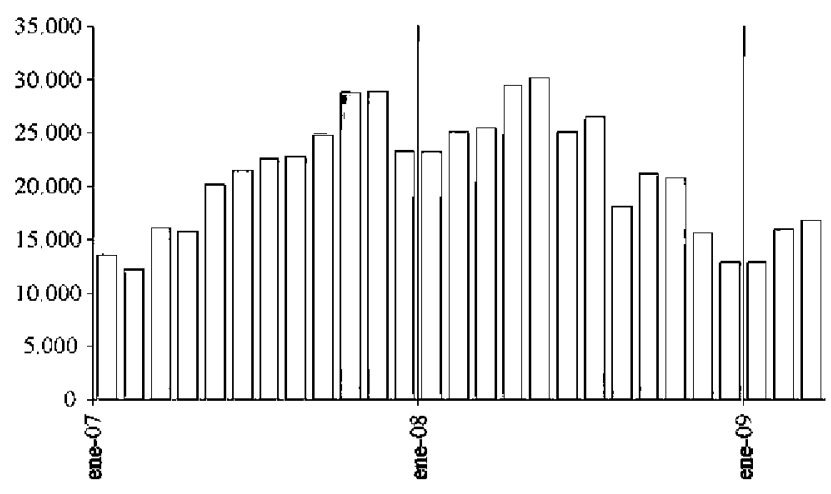

Fig. 17. Biodiesel and biodiesel blend monthly consumption (t) - January 2007March $2009-27$ pairs of points. Source: coreses [11].

\section{Results}

Although there are substantial differences between the U.S. market and the Spanish market, some relations have been observed.

\subsection{Related to the crude oil quotation}

Table 1 shows the crude oil quotation relationships.

Fossil fuel quotations are highly correlated to crude oil quotation. These correlations are positive correlations. Hence, the higher the oil quotation, the higher the fossil fuel quotations and vice versa.

There is no correlation between biofuel prices (at gas stations) and crude oil quotations. When the crude oil quotation dropped sharply $(-58.11 \%)$, E85 was slightly more expensive and biodiesel slightly cheaper. Hence, it is proven that a sharp decrease in crude oil quotation causes a loss of competitiveness in biofuels.

Crude oil quotations and the biofuels raw materials weighted average quotations are correlated. These correlations are positive correlations. Hence, the higher the crude oil quotation, the higher the biofuels raw materials weighted average quotations and vice versa. The correlation between average quotations of raw materials to produce ethanol and the oil quotation is higher that the correlation between average quotations of raw materials to produce biodiesel and the oil quotation.

\subsection{Related to the public aids to biofuels}

Tax exemption for biofuels in Spain has not caused them to penetrate significatively in the automotive fuel market. If this tax exception is not extended (it will be eliminated in December 2012), biofuels would be significatively more expensive than fossil fuels

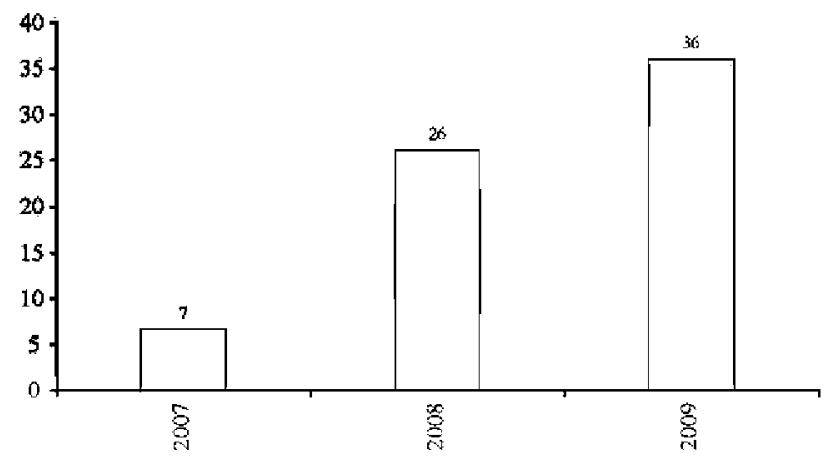

Fig. 18. E85 monthly average consumption per year (t) - January 2007-March 2009 - 27 pairs of points. Source: cores.es [11] and authors.

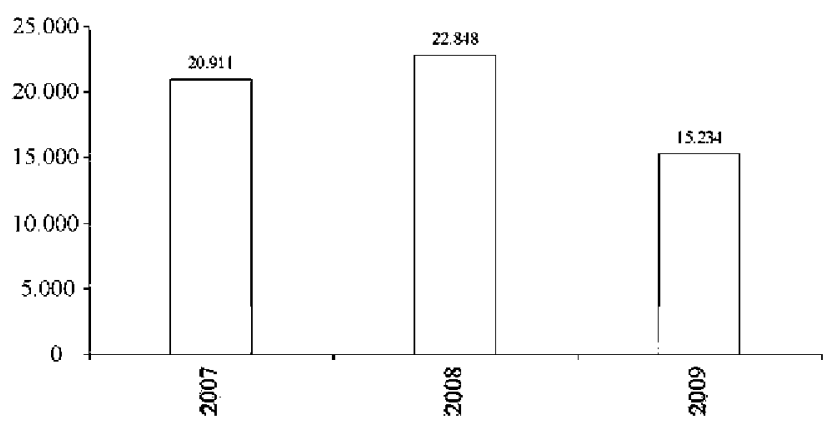

Fig. 19. Biodiesel and biodiesel blend monthly average consumption per year $(\mathrm{t})$ January 2007-March $2009-27$ pairs of points. Source: cores.es [11] and authors.

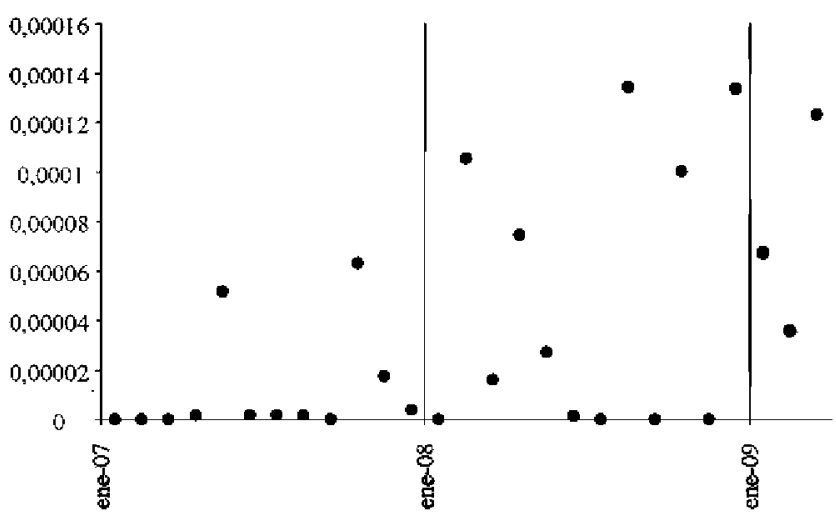

Fig. 20. Ethanol and ethanol blends consumption on the total consumption of fue for Otto cycle automobiles - January 2007-March 2009 - 27 pairs of points. Source: cores.es [11] and authors.

(in terms of price per unit of energy). Hence, a sharp decrease of biofuel consumption is forecasted and would eliminate them from the automotive fuel market.

\subsection{Related to the $\mathrm{CO}_{2}$ bond quotation}

Table 2 shows the $\mathrm{CO}_{2}$ bond quotation relationships.

Oil quotation is correlated to $\mathrm{CO}_{2}$ bond quotation. The higher the oil quotation the higher the $\mathrm{CO}_{2}$ bond and vice versa.

Gasoline 95 and diesel quotations are also correlated to $\mathrm{CO}_{2}$ bond quotations. This correlation is lower than the correlation of oil quotation and $\mathrm{CO}_{2}$ bond quotation.

Raw material quotations for biofuels used in Spain are correlated to the $\mathrm{CO}_{2}$ bond quotation. Ethanol raw materials

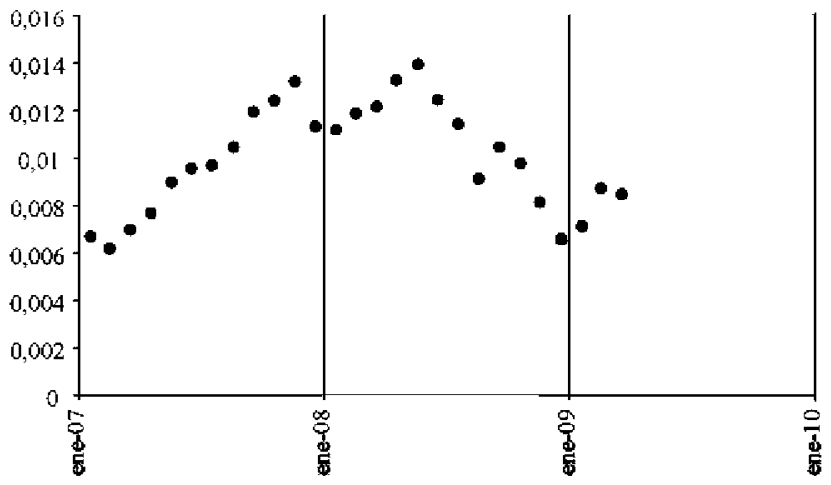

Fig. 21. Biodiesel and biodiesel blend consumption on the total consumption of fue for Diesel cycle automobiles - Janulary 2007-March 2009 - 27 pairs of points. Source: cores.es [11] and authors. 
Table 1

Crude Oil quotation relationships.

\begin{tabular}{|c|c|c|c|c|}
\hline Variable & Period & Data & $\begin{array}{l}\text { Pearson } \\
\text { correlation } \\
\text { coefficient }\end{array}$ & Kolmogorov-Smirnov (K-S) \\
\hline Gasoline 95 quotation & October 2003-March 2009 & 66 Pairs of points & 0.97 & $\begin{array}{l}\text { Significant with a confidence level of } 99 \% \text { ( } \alpha=0.01 \text {, } \\
\text { maximum type I error probability) }\end{array}$ \\
\hline Diesel quotation & October 2003-March 2009 & 66 Pairs of points & 0.97 & Significant with a confidence level of $99 \%(\alpha=0.01)$ \\
\hline $\begin{array}{l}\text { Ethanol raw materials } \\
\text { weighted average quotation }\end{array}$ & May 2007-July 2009 & 27 Pairs of points & 0.95 & Significant with a confidence level of $99 \%(\alpha=0.01)$ \\
\hline $\begin{array}{l}\text { Biodiesel raw materials } \\
\text { weighted average quotation }\end{array}$ & August 2004-July & 60 Pairs of points & 0.63 & Significant with a confidence level of $99 \%(\alpha=0.01)$ \\
\hline
\end{tabular}
Source: Authors.

Table 2

$\mathrm{CO}_{2}$ bond quotation relationships.

\begin{tabular}{|c|c|c|c|c|}
\hline Variable & Period & Data & $\begin{array}{l}\text { Pearson } \\
\text { correlation } \\
\text { coefficient }\end{array}$ & Kolmogorov-Smirnov $(\mathrm{K}-\mathrm{S})$ \\
\hline Crude oil quotation & April 2005-July 2009 & 52 Pairs of points & 0.76 & $\begin{array}{l}\text { Significant with a confidence level of } 99 \% \\
(\alpha=0.01, \text { maximum type I error probability) }\end{array}$ \\
\hline Gasoline 95 quotation & April 2005-July 2009 & 52 Pairs of points & 0.71 & Significant with a confidence level of $99 \%(\alpha=0.01)$ \\
\hline Diesel quotation & April 2005-July 2009 & 52 Pairs of points & 0.71 & Significant with a confidence level of $99 \%(\alpha=0.01)$ \\
\hline $\begin{array}{l}\text { Ethanol raw materials } \\
\text { weighted average quotation }\end{array}$ & May 2007-July 2009 & 27 Pairs of points & 0.89 & Significant with a confidence level of $99 \%(\alpha=0.01)$ \\
\hline $\begin{array}{l}\text { Biodiesel raw materials } \\
\text { weighted average quotation }\end{array}$ & May 2007-July 2009 & 27 Pairs of points & 0.28 & Significant with a confidence level of $95 \%(\alpha=0.05)$ \\
\hline
\end{tabular}

Source: Authors.

quotations are more highly correlated to $\mathrm{CO}_{2}$ bond quotation than biodiesel raw materials quotations.

An increase in $\mathrm{CO}_{2}$ bond quotation enables biofuels to be more competitive because their production generates $\mathrm{CO}_{2}$ bonds that can be traded. However, due to the correlation mentioned previously, an oil quotation rise means also a raw material quotations rise. Hence, there is no way to conclude how an oil quotation rises affects biofuel costs because two opposite forces appear: the $\mathrm{CO}_{2}$ bond rises and the raw material quotations rises. The first force makes biofuels cheaper and the second one more expensive.

\subsection{Related to the penetration of biofuels in the automotive fuel market}

The empirical analysis does not show that biofuels are gaining market share in the automotive fuel market: neither ethanol blends nor biodiesel are gaining quota against gasoline and diesel.

\section{Conclusions}

The results show that, at present, biofuels are not penetrating the automotive fuel market. Moreover, results show that the prices of raw materials used to produce biofuels depend on the oil quotation: the higher the oil quotation the higher the prices of the raw materials and vice versa. Furthermore, when there has been a decrease in the oil quotation, raw material prices decreased too but this decrease has not been transferred to the biofuel price.

It is also concluded that there is no reason to think that biofuels will become competitive in the future. Moreover, if the tax exception is not renewed by 2012, biofuels will be out of the market.
The use of hydrogen in the automotive industry is an alternative to fossil fuels and biofuels. Hydrogen can be used in an internal combustion engine and in a fuel cell. This use of hydrogen has been already analyzed by the authors in a previous report [12].

\section{References}

[1] Hernández Sobrino F, Rodríguez Monroy C. Critical analysis of the European Union directive which regulates the use of biofuels: an approach to the Spanish case. Renewable and Sustainable Energy Reviews December 2009;13(9):2675-81.

[2] Hernández Sobrino F, Rodríguez Monroy C, Hernández Pérez JL. Análisis técnico y económico del etanol y del biodiesel como sustitutos de combustibles fósiles para automoción en España. DYNA Ingeniería e Industria. November 2009.

[3] 2003/30/EC Directive of the European Parliament and the Council - May 8, 2003 on the promotion of the use of biofuels or other renewable fuels for transportation.

[4] Ray Szulczyk K. Market penetration of Biodiesel and ethanol. Ph.D. Thesis, Texas A\&M University; 2007

[5] Monthly reports on fuel prices - Spanish Ministry of Industry, Tourism and Trade - Ministerio de Industria, Turismo y Comercio. - http://www. mityc.es/energia/petroleo/Precios/Informes/InformesMensuales/Paginas/ IndexInformesMensuales.aspx - Last access: May 25, 2009.

[6] Oanda - http://www.oanda.com/convert/classic - Last access: May 3, 2009.

[7] ECX.eu - http://www.ecx.eu/EUA-Futures - Last access: August 13, 2009.

[8] Canton A. Cooperativas agro-alimentarias 30-7-08 - http://www.ccae.com/ Last access: May 20 2009; 2008.

[9] Lechón Y, Helena C, de la Rua C, Lago C, Izquierdo L, Sáez R.M. et al. Análisis de Ciclo de Vida de Combustibles Alternativos para el Transporte. Fase II. Análisis de Ciclo de Vida Comparativo de Biodiésel y Diesel. Ciemat - Centro de publicaciones - Ministry of the Environment; 2006 - http://publicaciones. administracion.es [Last access: may/05/2009].

[10] Ecx.eu - http://www.ecx.eu/ - Last access: 13 August 09

[11] Cores.es - http://www.cores.es/adjuntos/Consumos\%202007.xls Last access: May 26, 2009.

[12] Sobrino FH, Monroy CR, Hernández Pérez JL. Critical analysis on hydrogen as an alternative to fossil fuels and biofuels for vehicles in Europe. Renewable and Sustainable Energy Reviews 2009 December;13(9):2675-81. 